\title{
Philosophy of Technology: Modern Technological Reality and the Regularities of Development
}

\author{
Tatiana Malkova \\ Bauman Moscow State Technical University \\ Moscow, Russian Federation \\ 5/1, 2nd BaumanskayaStr. \\ Moscow, Russia 105005 \\ E-mail: t.p.malkova@yandex.ru
}

\begin{abstract}
While analyzing the phenomenon of engineering and technological reality, the relevance of developing such specialized discipline as the philosophy of technology in terms of ecological science is substantiated. Modern interpretations of the phenomenon of technological reality are given alongside with the author's understanding of new tendencies in its changes. The subject of technological creative work is focused on. The last mentioned is considered to be the bearer, consumer and creator of technosphere and infosphere, and is capable of changing the ecological environment. The current problems and the latest regularities of the development of science are stressed. The necessity of further development of the philosophy of technology is proved in terms of studying technosphere as part of being in order to control new technological reality more effectively.
\end{abstract}

Keywords-philosophy of technology; ecological science; technology; technical reality; matrix of the philosophy of technology; subject of creativity; regularities of technosphere development; technology-centered civilization

\section{INTRODUCTION}

The phenomenon of engineering and technology as the ability to create artificial objects dates back to the dawn of mankind. Man needs artifacts which could help him to save himself and his family not only in the natural environment but in the conditions of existence amongst other, often hostile, societies. Representatives of Homo Sapience don't possess the instincts necessary for survival; unlike animals, they lack their own behavioral type, innate arms and means of defense. All the history of mankind is the history of creative work, including technology and engineering. It facilitated human adaptation to the world, made the habitat adapted for the growing biological, social and cultural needs. Technology, as phenomenon, became the object under study only in the 19th century when such discipline as the philosophy of technology appeared[1]. In the 21st century the problems studied by the philosophy of technology are of special importance, because technology-centered civilization with the global techno- and infosheres has been created. It influences ecological aspects vitally important for human beings. Philosophy of technology or philosophy of technology and engineering is an established term denoting one of the directions in modern science [2]. As we think, the discipline is part of environmental science (or ecoscience) and requires further development. In the article the task of investigating theoretical problems is set. The problems are as follows: revealing the laws of the development of technology, engineering and technological activities, designing and putting designs into practice. It is important to analyze the development trends in technological and engineering sciences for better understanding what place they occupy in the culture of modern society, because mankind is moving towards the seventh techno-economic paradigm. Robotics, biocomputers, experiments in connecting AI to "living" systems are being rapidly introduced into technological reality in the course of scientific-technological progress. This fact makes the investigation in the area of the philosophy of technology especially significant.

\section{The PHILOSOPHY OF TECHNOLOGY: MODERN THEORETICAL PROBLEMS}

"Technosciences" are in the vanguard of the development of civilization which is directed towards the new technological paradigm in the course of the fourth industrial revolution (Industry 4.0), characterized by the appearance of smart houses, plants, cities, and grids. Cyborgs of all kinds interact with people. This is one of the newest trends in the investigation into the theory and practice of the philosophy of technology [3]. Not only the interactions of man and technology, nature and technology, but also various transformations of culture appeared under the influence of recent technological achievements. The ecological and ethic aspects of putting designs into practice are of primary importance because technology-centered civilization has given birth to numerous global problems, caused not only by the development of technology but also by the usage of it in terms of affecting man's habitat. Among those problems one can mention educational, psychological, communicative and some others. Of current interest are: the investigations of inner and outer factors of cultural influence on the development of technology, the theory of invention and the analysis of means of stimulating engineering and technological creative work. All of them have been developed in the modern concepts of creativity. 
The analysis of literature on the problems of the philosophy of technology allows the author to give the following understanding of the subject matter of the discipline. The philosophy of technology is a special philosophical discipline that studies the spiritual aspects of techno science and technological aspects of world outlook (ontological, gnoseological, axiological, ecological and existential ones), the essence of technology and the stages of its evolution. This is the sphere of certain rational activity where valuable, practical-pragmatic, communicative, ethic foundations of the "technological world" are realized. There emerges a very creative complex of ideas concerning the "technological world"(techne), and they also form a symbiosis of artificial and primordial nature. The philosophy of technologies is not only concerned with what modern technology is, what the essence of living and technical matter (bio-, techno- and infoshere)is, but also with how technology is built into man's being and mankind as a whole. It is also concerned with preserving ecological balance, the prospects of developing technology and the possibility of humanization of technological reality. Nowadays the subject matter of the philosophy of technology is defined, whereas the discipline is being filled with modern content; its close interrelations with ecoscience being revealed [4].

The newest investigations into the area of the philosophy of technology will allow us to have more complete and deeper understanding of technology and "technological", and the research tasks. Interpreting the term "technological", we would proceed from the existential and dynamic nature of man - the subject of technological creativity. Between man and the result of his activity there is an intermediate element - activity. The subject interacting with primordial and artificial nature -the world of culture and technologyaccumulates knowledge. Being combined and creatively transformed in mind, knowledge may change human nature. When objectivized, knowledge and skills of man form a new world of technological reality; objectively determine the life and behavior of an individual within a certain historical context. Ideal models, idealized objects of future technological systems, are always in the process of creation. Mental constructions come into being in the form of programs, drafts, models and development types. Their utility, operational comfort, ergonometry, the possibility of application are tested [5]. Any artificial object contains the ideas of its creator. The task of a consumer is to decode them. I.e. any technological object has some implicit.

Techne doesn't just possess some technical meaning. It is one of the means of concealing and revealing the conception of an artificial object, options for using it. At first, the ideas contained in an artifact were realized through material, form or function, but with the development of culture, technological objects acquire more and more purports and concepts (sign-symbolic system). The last mentioned depend on the level of scientific development, certain mentality, language and type of rationality [6].In the course of the cybernetic and digital revolution, modern technology enhanced implicit in its objects due to the sign-symbolic systems. Having studied and defined the level of modern technology, forms of its objectivization, man will be able to perceive the degree of technological novelty, positive and negative influence of innovative technologies on human creativity. Relying on the appropriate level of scientifictechnological knowledge, man will make it possible to use technology effectively for the benefit of people and avoid breaking the ecological balance within the boundaries of his new habitat [7].

\section{SPeCIFIC NATURE OF THE SUBJECT OF TECHNOLOGICAL ACTIVITY}

Nowadays one of the most important tasks of the philosophy of technology is to contribute to the formation of the subject adequately functioning (using digital technologies comprehensively) in the new technological reality. In terms of gnoseology, it is necessary to note that technological activity forms the basis for the modern body of important knowledge. From a historical perspective, it is technology that has generated the body of knowledge and become the source of development for technological sciences and the subject-creator of technological reality.

The investigation matrix of the technological philosophy includes the following components: nature, engineering, creative activities of the subject-creator, subject-bearer and consumer of a wide variety of interdisciplinary knowledge, including technological one. The subject of technological activity is of a tripartite nature. While analyzing the nature of technical reality and focusing on the interaction of its elements, it is also necessary to enlighten the coexistence of primordial and artificial, technical, reality. The modern subject more actively functions within technical reality, which comprises virtual reality as well. He always faces the necessity of decoding a diversity of meanings and implications, which were created by other subjects for him and before him. Theoreticians say that in the epoch of computerization, a lot of people place computer algorithms and digital content above the subject's personality. They identify their inner world with the information contained in various devices and gadgets, can't imagine their being without a computer and iPhone. This represents the problem of inner ecology of man, the problem of realization of human essential characteristics [8].

The positive development of technological reality can't be denied, but at the same time it's impossible not to ponder over concomitant negative tendencies. They appear in everyday life of the subject. The tendencies are as follows: degradation of education; learners have a diminished ability to remember, think, and handle problems; the dominance of clip thinking; the growth of functional illiteracy and inability to communicate; autonomism within the boundaries of smart house, etc. People spending more and more time on their computer devices become computer addicts. They don't bother about their spiritual and self-development or improving personal qualities, they think technology would correct all the mistakes in education and upbringing. Technical man suffers from psychophysical problems and declined natural biological activity.

Technological progress shouldn't be left to take its own course. Man is bound to control the changes in technological 
reality. It is obvious that the ideas born in subjects' minds can cause changes in being if it is possible to objectivize them as artifacts and introduce them into the reality of modern world. Just technical devices and innovations can't cause such changes. Introduction into civilization doesn't imply acquiring and using devises with numerous quantitative and qualitative options. Civility comes with upbringing, education, transmission of knowledge, creating consciousness and thought, focused development of the subject's technological and engineering creativity. To that bear witness the great leaps in the area of science and technology of such Asian tigers as China, Singapore and Southern Korea. It is known that as soon as China stopped buying machinery from the Weston traditional scheme and started to reconstruct its economic, educational and technological spheres, the growth in economy and technology was registered. Let's hope that Russia in the situation of import substitution will find the power to reconstruct thinking and worldviews, systems of functioning of science and technology, the last mentioned being the foundations for scientific and technological progress [9]. Progress, first and foremost, should provide subject of technological creativity with versatility of personal development. It is necessary to understand and take into consideration the downward tendency in the amount of time required for a new invention to appear and the upward trend in technological progress. As a result, new ecological problems emerge, and the demands for intellectualization and creativity of the subject-creator of technological objects increase.

\section{REGULARITIES IN THE DEVELOPMENT OF TECHNOLOGY AND TECHKNOWLEDGE}

Let us highlight some of the most important regularities which have appeared in the development of technology and techknowledge. Mankind has already come up to the idea of comprehensive modeling of technosphere as a whole. The demand for system organization of interaction between theoretical and empirical bases emerges. Interdisciplinary and integrated character of technological knowledge is being strengthened; transdisciplinary methodologies are appearing due to the development of technological science in the epoch of post-non-classical scientific reality [10], [11]; the role of mathematical and computer modeling is increasing. The dependence of the development of technology and techknowledge on NBIC (nanotechnology, biotechnology, information technology and cognitive science) has appeared. At the same time robotics, medical and genetic technologies are becoming more wide spread. It is necessary to stress the appearance of such specific phenomenon as the convergence of technologies, i.e. the focus on fundamental pluralism of methodologies and technologies in modern science and technology.

Not only information is important, but also the understanding of possible occurrence of such phenomenon as technological singularity, i.e. superintelligence capable of substituting, transforming and improving basic mental functions of man [12]. The occurrence of super intellect in the nearest decades sets the task of investigating traditional human identity and the changes inessential biosocial characteristics which have been denoted in terms of modern technology-centered society [13].

The researches claim that changing technical reality not only enriches and develops human abilities, but also leads to the loss of numerous biological and subjective skills acquired in the course of thousand-year socio-cultural evolution. Science and technology affect man not only from outside, but also from inside breaking the ecological balance of being. A lot of IT developments have appeared in the last decade. They allow man to be closely interconnected with cyberspace. Such integration causes certain consequences. On the one hand computers, robots, AI facilitate life: calculators count faster, mobile devices make communication easier, tablets and computers make the life of various specialists free for creativity. On the other hand if one delves deeper into the problem, then he'll see certain negative aspects. Man gradually loses his individuality under the influence of various clichés imposed on him by electronic devices, computers and objects with AI [14]. Communication by texting and messaging don't bring people together. Communication becomes primitive and loses its main functions of psychological, emotional and spiritual contacts. Moral values included in the being of Homo Moralis degrade; to mention just a few: shame, remorse, honour, trustworthiness, etc.

The boundary between natural and artificial in man blurs. He isn't just a product of the technological environment any more, but designing and creating new technological reality, he becomes a product of his own creative activity. Even man's physiology may be changed due to identity chips and AI-controlled implants, genetic technology, transplantology, etc. Science is "attacking" man. There are some difficulties in considering a living being to be man. The problem emerges when artificial organs are implanted, and the question arises: to what extend a person with tissues and organs substituted by mechanical, cybernetic and bionic components can be considered man [15]. 3D printer usage makes it possible to put a technological idea into life not only in the form of some physical object but also in the form of a bionic one. The symbiosis of man and technology is another important problem of the modern philosophy of technology [16].

Digital technologies are changing the world dramatically: informatics is going to serve as the fundamental of any science, the digital revolution is developing at a rapid rate, and quality of AI devices is being improved [17]. Modern technical reality is becoming more and more dependent on international Internet companies. Due to the Internet, there's a constant growth of opportunities to put any ideas into being, either in the form of hardware or virtual models with the help of the programs that are constantly developing. The use of digital technologies in economy and the appearance of various kinds of cryptocurrency in the world market require a serious theoretical analysis.

The idea of innovative activity is being planted into the minds of people, active subjects of scientific and technological creative work. This idea is being successfully 
put into practice in the "silicon" scientific centers. Uncontrollable anarchy in terms of the Internet creativity emerges in the world where digital content is constantly produced, transferred and consumed. Ecological and humanitarian assessments should become obligatory when it concerns new technological projects. The comprehension of these processes, their study and analysis is the challenge for the philosophy of technology which is considered a specialized scientific discipline related to ecoscience. The most important regularity in the development of technology is not only the connection with practice and material needs, but also a growing dependency of the social development on the level and character of support on the part of the state and private capital [18]. Only educated, highly moral and free person can control scientific and technological progress. True progress and economic, political and spiritual slavery are in contradiction with each other, they are incompatible in the real life.

\section{CONCLUSION}

Investigations in the field of the philosophy of technology, understanding of aims and tasks of the development of the discipline contribute to the comprehension of the personality's role, the necessity of good education in the modern information technological world [19]. This is the conclusion drawn from the analysis of the actual problems of the discipline under consideration: man in the 21 st century should be not only intellectual, professional and creative, but also moral, humane, ecologically educated. Personal development of an individual as subject is of primary importance, but not general statements and calls for modernization of the society and innovation activities. There's reasonable certainty that the problem can be solved by consolidating the efforts of the state, society, intellectual elite and interested in progress public figures. It is necessary to initiate national programs providing for the development of general culture, education, science, social mentality and spiritual world of man. It would be very useful to introduce such discipline as philosophy of technology into the curricula of technical universities.

\section{REFERENCES}

[1] Engelmeyer P. K. Do We Need the Philosophy of Technology?//InzhenernyiTrud- Engineering Activity.1929.№ 2.P. 36-40.

[2] MitchamC. What is the Philosophy of Technology?Moscow: Aspectpress. 1995 .

[3] Mal'kova T. P.Cyberzation: Philosophical Aspects ofInvestigation of the Symbiosis of Man and Technology // Humanitarian Herald.2017.№ $\quad 4.4$ Available at: URL: http://dx.doi.org/10.18698/2306-8477-2017-4-426. DOI: 10.18698/2306-8477-2017-426.

[4] Lebedev S.A. The Reassembly of the Epistemology // Voprosyfilosofii. 2015. № 6. P. 53-64.

[5] Gubanov N.I., Gubanov N.N. Subjective reality and space // Voprosyfilosofii. 2015. № 3. P. 45-54.

[6] Gubanov N.I., Gubanov N.N. The role of mentality in the development of society: sociocultural hypothesis // Vestnikslavianskikh kultur-bulletin of slavic cultures-scientific and informational journal. 2017. Vol. 43. № 1. P. 38-51.
[7] Ovcharova, E. V. Positive and Negative Influence of Innovative Technologies on Man's Creativity in the Modern World // Proceedings of the 4thAll-Russia Scientific Conference on Actual Problems of Social Communication. Department of Communication Technologies of Nizhny Novgorod Technical University n. a. Alekseev. N. Novgorod: NNSTU Publishing House, 2013, P. 182-187.

[8] Oseledchik M.B., Ivlev, V. Yu.,Ivleva, M.L. A new paradigm for analyzing knowledge transfer processes // Proceedings of 4th International Conference on Education, Language, Art and Intercultural Communication (ICELAIC 2017)Part of the series ASSEHR. Moscow, Russia. P.766-770.

[9] Suzdaleva T.R. Migratory processes in the context of geopolitics // VestnikTomskogogosudarstvennogouniversiteta-Filosofiyasotsiologiya-politologiya-Tomsk state university journal of philosophy sociology and political science. 2016. № 3 (36). P. 237 244. DOI: $10.17223 / 1998863 X / 35 / 25$

[10] Chernikova I. V. Transdisciplinary Methodologies and Technologies of Modern Science // Voprosyfilosofii. 2015. №4. P. 26-35.

[11] Lebedev S.A. The Structure of Scientific Rationality // Voprosyfilosofii. 2017. № 5. P. 66-79.

[12] Bostrom N. Superintelligence: Paths, Dangers, Strategies. Moscow: "Mann, Ivanov, Ferber" Publishing House. 2016.

[13] Belyayev G. Yu. In Anticipation of Singularity: NBIC-convergence as the Challenge of the 21st Century to Traditional human Identity / Man and Society in terms of Contemporaneity. Proceedings of AllRussia Conference (with international participation). Moscow, 14 June, 2017.RUDN UniversityPublishing House. V. 2. P.261-272.

[14] Inozemtsev V. A., Ivlev, V.Yu., Ivleva, M.L. Artificial intelligence and problem of computer representation of knowledge // Proceedings of the 2017 2nd International Conference on Contemporary Education, Social Sciences and Humanities (ICCESSH 2017) Part of the series ASSEHR. Moscow, Russia. V. 124. P. 1151-1157.

[15] Bryzgalina E. V. Man as Frontier of Science and Education / Methodology in Science and Education: Proceedings of All-Russia Conference of Universities and Academic Institutes of the Russian Academy of Sciences. Moscow, 30-31 March, 2017. Moscow: BMSTU Publishing House. Federal Research Centre "Informatics and Control"of the Russian Academy of Sciences. Moscow: BMSTU Publishing House. 2017. P.3-8.

[16] Yudin B. G. Technoscience and Augmented man // Epistemology \& Philosophy of Science. 2016. № 2 (48). P. 18-27.

[17] Volkov A. "Silicon" Scientific Centres and their Consequences// Scientia - Potentia Est. 2014. №11. P.4-12.

[18] KokoshinA. A. Interactions of Politics and Military Strategy: Problems of Theory and Practice.VoprosyFilosofii - The Problems of Philosophy. 2024. № 10. P. 2-13.

[19] Mal'kova T. P. Technical Education in the Information society / Methodology in Science and Education: Proceedings of All-Russia Conference of Universities and Academic Institutes of the Russian Academy of Sciences. Moscow, 30-31 March, 2017. Moscow: BMSTU Publishing House. 2017. P.200-203. 